Fuchs (loc. cit.), who showed that the last three stages had velocities proportional to the numbers of residual hydrogen atoms.

The point cannot definitely be decided until more complete experimental data are available. Further investigations are being carried out; these, it is hoped, will throw more light on the matter, or provide a different explanation.

The conclusions, however, are in harmony with those of Harkins and Bowers 4 on the carbon-halogen bond as related to Raman spectra, in that the frequency of the $\mathrm{C}-\mathrm{Br}$ bond is constant in normal compounds with the exception of $\mathrm{CH}_{3} \mathrm{Br}$. The results of West and Farnsworth ${ }^{5}$ on normal chlorides show that the frequency of the $\mathrm{C}$-Cl bond is constant except in methyl chloride.

J. MAsON.

Department of Oil Engineering and Refining,

The University, Edgbaston, Birmingham, Dec. 9.

1 Mason and Wheeler, Jour. Chem. Soc., 2282; 1931.

Pease and Waltz, $J$ Am. Chem. Soc. 3728; 1931.

Martin and Fuchs, Zeit. für Elektrochemie, 27, 150; 1921.

4 Harkins and Bowers, J. Am. Chem. Soc., 2425; 1931. Physical

Review, 38, 1845; 1931 .

5 West and Farnsworth, Trans. Faraday Soc., 27, 145; 1931.

\section{Preparation of Sulphuric Acid free from Nitric Acid.}

For the analysis of the nitrate content of sea water, and for certain tests on alkaloids, it is necessary to have sulphuric acid free from all but the most minute amounts of nitric acid. After testing a number of British and foreign samples of pure sulphuric acid, Harvey ${ }^{1}$ reported that he had found the "nitrogen free' sulphuric acid specially supplied by the British Drug Houses, Ltd., to be satisfactory, though the 'analytical reagent' acid was not so. Even in the purest acid the reduced strychnine reagent of Denigès demonstrated the presence of nitric acid, which was estimated by extrapolation after adding known amounts of nitrate, reckoned as milligrams of nitrate nitrogen per cubic metre of sea water.

Early this year I encountered the same trouble owing to nitric acid when applying the diphenyl benzidine method of Letts and Rea ${ }^{2}$ to the estimation of nitrate in sea water. It was found, however, that all nitric acid could be removed from the sulphuric acid by the cautious addition of ammonium sulphide. It was later found preferable to use hydrogen sul phide. This reduces the nitric acid, and the amount of sulphur formed is too small to be visible or to render the acid even slightly turbid. In practice it is better not to remove all the nitric acid, but to leave a trace sufficient to give the faintest perceptible colour with the reagents. Excess of the reducing agent would, of course, render the test insensitive through the production of sulphur dioxide. The last supply of 'nitrogen free' acid received gave no perceptible colour with the reagent after standing for a day.

\section{Marine IBiological Laboratory,} Plymouth, Dec. 12.

1 Jour. Marine Biol. Assoc., 14, 72 ; 1926.

2 Jour. Chem. Soc., 105, 1157; 1914 .

\section{National Needs.}

I. AM glad to have occasioned the rejoinder of H. E. A. in NATURE of Dec. 26, though I am frankly horrified at his proposal for a coup d'Etat followed by the dictatorship of the Royal Society. I fear the adventure would end with that august body in the tumbrils.
H. E. A.'s other suggestion, that there should be inaugurated a kind of educational crusade to develop the scientific attitude of mind in the ordinary citizen, is one of the most important ever made to the world of science. In spite of the immense social irnportance of the work and temper of science, her disciples do not make any effort to explain themselves to the public comparable with the electioneering effort of a political party or the missionary effort of a church.

Something more is needed than gentle remonstrances addressed to schools and universities, begging them to include some science in the courses followed by their non-specialist students. Schools and universities are only part of the wider problem of the in sufficiency of public thought to manifest social needs. I should like to see the scientific world dealing with the public mind by every modern device of persuasion, including school, university, press, radio, cinema, and the various institutions for adult education, in an organised attempt to influence the thought of this generation. I believe that such an effort, generously conceived and carried into effect, would be astonishingly successful.

I share the doubt, expressed in the leading article in the issue of Jan. 9, as to the appropriateness of the Royal Society as a pivotal body for such a task. The Society could contribute the reflected glory of its immense prestige, but so far as I know it possesses no machinery for carrying out this kind of work.

The various concrete projects which peep out from time to time from beneath the generalities of the present discussion could be carried through by a comparatively small group of people, with the assistance of allies called into co-operation for special purposes. The members of such a group would need to be people of scientific training with a flair for public work and with the proper contacts within and without the scientific world. It would not be difficult to find a score of such men and women. The really difficult problem would be to finance their work. Such expenditure would in the end repay the scientific pro. fession very handsomely in hard cash.

Birmingham, Jan. 5.

Louis Anderson Fenn.

\section{Discovery of Eurytemora thompsoni at Lancing.}

THE discovery of Eurytemora thompsoni by Mr. Lowndes at Lancing 1 adds one more puzzle to the problem of the distribution of the fresh- and brackish. water fauna. A rather similar case of unaccountable distribution is that of Acartic tonsa, a copepod which was discovered in 1927 in brackish water in a canal at Caen (Normandy). This is a coastal species of very wide distribution, recorded from the Pacific, Indian Ocean, and North American coast of the Atlantic, but not from its eastern shores. In the case of the anemone, Sagartia lucice, the agency of ship transport is fairly obvious; but it is not very convincing for Calanoid copepods, especially when, as in the case of E. thompsoni, the locality has no connexion with any harbour. Still, such transport cannot be excluded. I have found $S$. lucioe myself in a brackish pond in Norfolk far from any port.

It may be worth mentioning here that I specially looked for, and found, S. lucioe in Port Said harbour, though it is not mentioned in the reports of the Cambridge expedition to the Suez Canal. Presumably the specimens were lost.

Boars Hill, Oxford.

Robert GuRNer.

Nature, 128, 967, Dec. 5, 1931.

No. 3246, VoL. 129] 